\title{
Que producir, como producir y para quién producir... el caso del frijol
}

\author{
Daniel Flores
}

En toda organización social exisle un debate que lleva ya muchisimos anos, desde que aparece la economla como ciencia: la mayorla de las personas en general sólo llenen una ligera ldea sobre lo que es economla y el papel que juegan los economistas en éste complicado mundo, la gente común creen que la economía liene que ver con cuestiones de dinero, otras la asocian con los negocios, el gobierno, la educación, elc.

De esta serie de apreciaciones sobre el quehacer de la economla se puede desprender el papel clave que ocupan los economislas en toda la organización social, pero, independientemenle donde ésle pueda desenvolverse tendrá que airontar una problemálica que es común a la totalidad de la ciencia económica y a toda sociedad moderna: la cual viene dada por tres problemas básicos expresados en tres preguntas, a saber: ¿Qué bienes y servicios deben producirse? La segunda ¿Cómo debe producirse? Y la última ¿Para quién debe producirse?

Resulta oportuno pregunlarse ¿Por qué son problemas?, la razón es que dicho cuestionamiento nos está presentando un conllicto entre deseos ilimitados de las personas por tener bienes y servicios trente a recursos escasos necesarios para atender las necesidades de la colectividad. El planteamiento de dicha problemálica cobra mayor prolundidad en aquellos países subdesarrollados como el nuestro, donde la escasez de recursos y el alrazo tecnológico vuelven dilicil abastecer de bienes y servicios a la sociedad. Sirva pues éste pequeno bosquejo inlroductorio para iniciar el contenido de la presente investigación, en la que resalla- 
resaltaremos la problemática que afronta la población salvadoreña en relación con el encarecimiento de los granos básicos en general y particularmente el frijol.

\section{Importancia del frljol dentro de la allmentación básica}

En un pals como el nuestro cargado de graves problemas sociales, económicos y políticos, hablar sobre el funcionamiento del mercado de granos básicos viene a ser un tema que provoca reacciones a favor o en contra, según sea la ubicación social en la que se encuentra un determinado agente económico. Concretamente, enfocar la problemática del frijol se vuelve importante por dos razones: primero, porque forma parte de la dieta básica de todos los salvadoreños y segundo, porque la producción de éste grano es realizada en su totalidad por pequeños productores que dependen de la venta de su cosecha para cubrir costos y a su vez alimentar a su grupo familiar.

Siendo un bien clave para asegurar la seguridad alimentaria de la población, resulta detonante la actual distorción de precios (enero de 1993 2,50 - octubre 1993 7,0), ya que el impacto recae principalmente sobre el consumidor final que no tiene otra alternativa más que, sacrificar aún más su ya deprimido consumo o sustituir el frijol por otro bien. En el Indice de precios al consumidor (IPC) quedan estructurados los pesos de los principales bienes que conforman la canasla básica, éstos pesos o apreciaciones reflejan la importancia que lienen los bienes en los gastos de las unidades familiares.

\section{Cuadro $N^{0} 1$}

Indice de precios al consumldor (año base 1978)

\begin{tabular}{cr}
\hline Composición de la canasta básica & Pesos \\
\hline Alimentos & $41.44 \%$ \\
Vestuario & $23.04 \%$ \\
Vivienda & $7.04 \%$ \\
Miscelaneos & $28.34 \%$ \\
General & $100.00 \%$ \\
\hline
\end{tabular}

Fuente: Digestyc

De tal manera, puede observarse que del total del gasto, el $42 \%$ es absorido por el rubro de alimentos; en términos nominales, del gasto base $(3,169.55)$ para el Indice de la canasta básica de mil novecientos noventa y dos; $\$ 137.71$ (FUSADES 1993) son destinados para la com- 
pra de frijoles, lo que consideramos que es una cantidad significativa de cara ha mantener la estabilidad en el costo de vida de la población salvadoreña, el tema toma un matiz dramático cuando nos trasladamos hacia aquellos estratos de la población que no tienen el privilegio de contar con un ingreso tijo, sino, por el contrario, se debaten entre la miseria y la muerte, para vergúenza nacional, éste grupo social lo conforman la mayorla de sus habitantes, que por su mismo estado de marginación social se vuelven más vulnerables a situaciones como las que hoy experimentamos con el elevado precio del frijol.

\section{¿Qué producir y en qué cantlded?}

Uno puede preguntarse hacia quien va dirigida el anterior cuestionamiento y con sinceridad tendriamos que responder, hacia todos los que contormamos éste pals, pues procurar la satisfacción de necesidades debe ser preocupación de todos. Sin embargo, las sociedades modernas se caracterizan por una compleja división social del trabajo, ello implica delegar funciones y responsabilidades en nombre de la sociedad, de tal manera, las grandes orientaciones del conjunto social son tomadas por aquellos que se atribuyen la representatividad del cuerpo social, es decir en éste estado de evolución económica le compete al Estado.

Siendo el Estado cabeza del cuerpo social es pues el responsable de la conducción y el desarrollo de la nación, para ello legisla, administra y ejecuta acciones concretas de cara ha encontrar el bien común. Es innegable entonces, la gran responsabilidad que tiene el Estado en aras de crear las condiciones materiales que posibiliten la reproducción de la sociedad.

En nuestro pals está ocurriendo un fenómeno económico que pone en duda el papel y/o la responsabilidad del gobiemo salvadoreño en procurar la seguridad alimentaria de los habitantes de ésle pais, tal situación puede resumirse de esta manera, a partir de febrero del presente año los precios del frijol se han disparado en el mercado, afectando sensiblemente el poder adquisitivo de la población, sobre todo, de las mayorlas populares del pais; ya que el Irijol es consumido $100 \%$ en el área rural y en un $90 \%$ en los hogares que se ubican en el área urbana. 
Cuadro $N^{2} 2$

Evoluclón de los preclos del frljol pagados por el consumidor

\begin{tabular}{|c|c|c|c|}
\hline Anos & Precio/Lb. & Anos & Precio/Lb. \\
\hline 1980 & 1.16 & 1987 & 1.37 \\
\hline 1981 & 1.17 & 1988 & 3.02 \\
\hline 1982 & 1.00 & 1989 & 2.28 \\
\hline 1993 & 0.86 & 1990 & 2.82 \\
\hline 1984 & 0.83 & 1991 & 3.28 \\
\hline 1985 & 0.99 & 1992 & 1.99 \\
\hline 1986 & 1.27 & 1993 & 4.90 \\
\hline
\end{tabular}

Nota: precios promedios anuales, 1993 de enero-oct.

Fuente: Dirección General de Economla Agropecuaria, División de Análisis de Mercado. MAG. 1993.

Al hacer una revisión histórica del comportamiento de precios del frijol pagados por el público consumidor, nos encontramos con lo siguienle: durante el periodo en esludio es posible apreciar que los precios de adquisición por libra ha venido sutriendo alteraciones en su nivel promedio anual. De 1.16 pagados en 1980 hemos pasado a 4.90 durante los primeros diez meses de 1993, es decir una variación de $322.4 \%, 10$ que significa en términos de acceso al mercado de granos básicos una creciente diticultad en el aprovisionamiento de frijol y por ende un menoscabo en las condiciones de vida de la población. Tomando en cuenta que el trijol es un alimento estratégico para la dieta alimenticia del salvadoreno promedio; es de suponer que las personas, han tenido que sacrificar otro tipo de gasto (diversión, educación, salud...) para ajustarse a ésta cambiante situación de los precios de adquisición del frijol.

SI bien es cierto, la problemática del frijol queda expresada en términos de alzas continuas de precios, no hay que suponer que la solución será únicamente proponer una adecuada politica de precios (precios de sustentación, bandas de precios, elc.), sino por el contrario, la problemática del trijol debe abordarse de una manera integral, de tal manera que se abarque la parte monelaria financiera y su contraparte el sector real de la economia; lo anterior pasa por fomentar el crecimiento del producto agricola.

Como se sabe, los precios al productor no son el único instrumenlo 
de política económica para el fomento de la producción, hay otros factores de carácter más organizacional de la producción como son: la euperticie de therra dedicada a éste cultivo, la dílcultad de acceder al crédito bancario, el precio de los insumos, la asistencla técnica, la baja productivldad, elc.

Razón por la cual creernos necesario que la salida a la presente problemática es aumentar los volúmenes de producción y mejorar la distribución del mismo; con lo que se estarla posibilitando que los habilantes de este pals puedan solventar de mejor forma las exigenclas de su reproducción material; $b$ anterior nos involucra de alguna manera a dimensionar el problema de manera global, es decir, en términos de la seguridad alimentaria.

Por principio, el goblerno de El Salvador es el responsable de garanlizar la seguridad alimentaria de la población, pues si revisamos la Constitución Politica (1993) en su primer articulo reza lo sigulente:

"El Salvador reconoce a la persona humana como el origen y el fin de la actividad del Estado, que está organizado para la consecución de la justicia, de la seguridad juridica y del bien común." Asimismo to que alane al orden económico está descrito en los articulos 101 y siguientes, los cuales obligan al gobiemo a responder "esencialmente a principios de justicia social, que tiendan ha asegurar a lodos los habilantes del pais una existencla digna del ser humano* (ibid), de tal manera, que el GOES no debe renunciar a su compromiso de buscar el bieneslar de la mayorla de sus gobernados, teniendo muy en cuenta que al dejar al mercado determinar el qué y cuánto producir, es poner en juego no sólo parte importante de la diela básica de todos los salvadorefios, sino que, también se está condenando a la incertidumbre (distorsión de preclos en compra y venta) al mayor número de productores agricolas, ya que los granos básicos son generados en pequenas parcelas y por una intinidad de pequehos productores. Según Chong Dlaz (oct. 1992), "el $60 \%$ del total de productores de frijol se ubican en fincas menores de 2 manzanas". As 1 tenemos que "poca o inadecuada disponibilidad de tierra" (Rubio Roberto 1992) se encuentra fuertemente vinculado a la precariedad con que se desarrolla la producción de trijol en el subsector de granos básicos de la economía salvadoreha. Tal situación que se caracteriza por un pobre e ineslable crecimiento de la producción y de los rendimientos en el cultivo del Irijol a nivel nacional la podemos observa en la información que presentamos a cominuación. 
Cuadro No. 3

Datos sobre producción de frijol

\begin{tabular}{lrrr}
\hline Año Agricola & Superficie & Producción & Rendimientos \\
\hline 1980 / 81 & 75,000 & 866,000 & 11.6 \\
1981 / 82 & 71,000 & 831,820 & 11.7 \\
1982 / 83 & 79,400 & 830,000 & 10.5 \\
1983 / 84 & 80,500 & 918,300 & 11.4 \\
1984 / 85 & 82,500 & $1,056,000$ & 12.8 \\
1985 / 86 & 83,300 & 751,200 & 9.0 \\
1986 / 87 & 87,100 & $1,093,900$ & 12.6 \\
1987 / 88 & 89,300 & 531,000 & 6.0 \\
1988 / 89 & 96,100 & $1,240,000$ & 12.9 \\
1989 / 90 & 91,600 & 968,900 & 10.6 \\
$1990 / 91$ & 89,500 & $1,145,400$ & 12.8 \\
$1991 / 92$ & 109,500 & $1,481,800$ & 13.5 \\
\hline
\end{tabular}

Fuente: MAG. Anuario de Esladísticas Agropecuarias 1990 - 1991.

Siguiendo en la línea de dar una respuesta la interrogante qué y cuánto producir, la información presentada en el cuadro anterior nos da señales suficientes como para interpretar que nuestros agricultores han decidido producir más frijol, pues la tendencia ha sido en estos últimos años a emplear una mayor superficie de área sembrada, razón por la cual la producción a tenido un comportamiento oscilatorio pero que tiende a hacia el alza. No obstante ésla mayor oferta, no debe llevarnos a pensar que en El Salvador tenemos garantizada la seguridad alimentaria, más bien, hay que leer dicho aumento como un intento de equiparar olerta y demanda. Pues a pesar de los aumentos observados en la producción, éstos no son suficientes para cubrir las necesidades de bienes alimenticios de origen agricola, de la creciente población. A manera de ilustración podrlamos calcular el consumo de frijol en términos "per cápita", y tendríamos lo suficiente para el año de 1991/92, a cada salvadoreño le correspondería un promedio aproximado de 2 libras de frijol mensualmente, cuando éste bien es de consumo masivo y diario en la mayor parte de la población. Lo que sin duda pone en tela de juicio lo anunciado recientemente por el Sr. Ministro de Agricultura, el cual pregonaba públicamente que "la pasada cosecha de frijol habla sido la más grande de toda la historia del pals". Contrariamente al optimismo oficial debemos decir que la autosuficiencia alimentaria no solo debe circunscribirse a la oferta de bienes, sino también a la capacidad de 
acceso que la población presente y futura tenga a la producción. Por lo tanto, la oferta de frijol en El Salvador ha sido, es y tendencialmente continuará siendo insuficiente $\theta$ imposible de garantizar la seguridad alimentaria. Lo escrito anteriormente nos anima ha pensar, que la problemática que vive la población salvadoreña referente al frijol, es un problema de escasez y también de precios, que obedece a múltiples factores como podrían ser: la estructura de costos, liberalización de los mercados de granos básicos, como producto de la implementación de las politicas de ajuste estructural, etc. algo de ellos abordaremos más adelante.

\section{¿Como produclr...?}

La lectura expuesta anteriormente debe llevarnos a la conclusión de que el problema de la agricultura en nuestro pais es bastante delicado y que abordarlo adecuadamente requiere de decisiones económicas, es decir, decisiones sobre el modo de emplear los escasos recursos para atender las necesidades de alimentación de la población. Resulla lógico pensar que si los recursos de la agricultura son limitados debe seleccionarse aquello que ha de ser prioritario, ello implica "adoptar procedimientos tecnológicos que permitan extraer en la mayor forma el máximo posible de su capacidad productiva a cada uno de los recursos".

Ciertamente el bien que está en discusión, muy a pesar de su importancia para el pais, es un producto que para su cultivo requiere un mínimo de empleo de recursos, el hecho que pequeños productores sean los generadores de dicho alimento popular, nos lleva ha suponer que el cultivo de frijol no parece rentable a los ojos del gran capital agricola. Siéndo asl, tendriamos que reflexionar que es lo que deseamos en éste momento de nuestra historia, queremos tener la capacidad de alimentar a nuestra gente o pensamos simplemenle en la captación de divisas como producto de la venta de bienes exportables al resto del mundo. Sin lugar a dudas las divisas son necesarias, pero la seguridad alimentaria no se puede posponer en el tiempo, pues la necesidad de alimentarse en las personas no puede esperar hasta que los frutos del crecimiento económico (basado en una vocación exportadora de todo bien que puede colocarse en el mercado mundial), se derrame y llegue a los más urgidos de consumir bienes alimenticios de origen agricola.

Si revisamos los datos sobre el destino del crédito en nuestro pals, vamos a reforzar empíricamente nuestra preocupación que bien podrla quedar resumida de la manera siguiente: la producción de granos básicos no se encuentra dentro de las prioridades de la cartera de préstamos del sistema financiero nacional. 


\section{Cuadro $\mathrm{N}^{2} 4$}

Destino del credito por sectores montos otorgados por BCA. CO. (Millones de colones)

\begin{tabular}{lrrr}
\hline Sectores de destino & 1988 & 1989 & 1990 \\
\hline Agropecuario & 937.6 & $1,303.0$ & $1,433.7$ \\
Minarla y canleras & 13.1 & 6.8 & 0.382 \\
Industria manufact. & $1,256.0$ & $1,162.8$ & 1,762 \\
Construcción & 282.5 & 252.0 & 179.6 \\
Elect. gas y agua & 2.7 & 1.8 & 14.5 \\
Comercio & $4,588.3$ & $6,780.3$ & $5,809.7$ \\
Transp. almacen. y com. & 50.9 & 51.3 & 48.3 \\
Servicio & 208.3 & 195.3 & 150.4 \\
Otras actividades & 872.6 & $1,002.7$ & 991.9 \\
\hline Total de crédito & $8,212.0$ & $10,756.1$ & $10,390.7$ \\
\hline
\end{tabular}

Fuente:. Revista Trimentral. Oct. - Dic. 1992.

\section{Polftica crediticla}

Una mirada rápida al cuadro anterior es suticiente para darnos cuenla de la existencia de una virtual clasiticación de los sectores económicos de acuerdo a su participación en la absorción del crédito bancario. Desde hace algunos años la actividad económica que ha acaparado los primeros lugares como sujelos de crédito a sido el comercio; por lanto, es oportuno pensar que ésle fenómeno presione a la terciarización de la economía salvadorena caracterizada por ser dependiente, Inunca, marginadora, concentradora y ahora también una economia de vendedores, obviamente nuestra capacidad empresarial se encuentra abocada a priorizar actividades especulativas, que por supuesto son más rentables, tal como la actividad comercial. En segundo lugar aparece la industria manufacturera y en tercera posición tenemos el importante sector agricola que absorbe un $13 \%$ del tolal del crédito olorgado; mientras el comercio se apropia de más del $55 \%$, evidentemente, las diferencias son claras y conlundentes como para afirmar que no existe una distribución del crédito balanceada, tal parece, que éste importante mecanismo no encaja dentro de los objetivos de la politica crediticia llevada a cabo por el GOES, la cual al parecer se está dejando guiar más por criterio de rentabilidad, propia de una economla de mercado, que por criterio de racionalidad económica. 
Si delimitamos aún más el deslino del crédito global al subsector de la agricultura, vamos a tener la siguiente información.

\section{Cuadro Ne 5 \\ Estructura del crédito agropecuarlo (1988-1990) (en porcentajes)}

\begin{tabular}{lrrr}
\hline Sector agropecuario & 1988 & 1989 & 1990 \\
Agricultura & 100.00 & 100.00 & 100.00 \\
a) Agroexportación: & 78.32 & 80.87 & 83.90 \\
- Caf́́ & 63.08 & 69.60 & 71.90 \\
- Algodón & 7.79 & 4.9 & 3.4 \\
- Cańa de azúcar & 7.45 & 6.37 & 8.60 \\
b) Granos básicos & 3.23 & 2.92 & 2.56 \\
- Maíz & 2.20 & 1.72 & 1.70 \\
- Frijol & 0.10 & 0.14 & 0.10 \\
- Arroz & 0.83 & 1.06 & 0.66 \\
c) Otros produclos agr. & 5.94 & 4.53 & 4.74 \\
d) Ganaderia & 4.58 & 2.73 & 1.33 \\
e) Avicullura & 4.38 & 5.76 & 4.8 \\
f) Pesca & 3.49 & 3.2 & 2.5 \\
\hline Total de Crédito & $100.00 \%$ & $100.00 \%$ & $100.00 \%$ \\
\hline
\end{tabular}

Fuente: Cálculos propios en base a datos tomados de BCR. Revista trimestral Oct - Dic. 1992.

La absorción de crédito de los granos básicos no pasa del 3\% de total de crédito agricola; dicha situación, se vuelve más crítlca, si vemos la participación de la producción de trijol en la estructura del crédito agropecuario, encontramos que, ésle no logra ni lan solo la unidad $(1 \%)$, pues, durante los últimos afios se ha mantenido con participaciones exiguas que tienden a ser cada vez menores.

Nadie podrá negar que el crédito del sistema bancario se orienta principalmente a financiar actividades agrlcolas de exportación, tal es el caso de los productos tradicionales de exportación (calé, algodón y cana de azúcar) que se apropian de un poco más del $80 \%$ del crédito agricola. Ciertamente, los hechos muestran una situación cab́tica para la producción de granos básicos, contrario a lo sostenldo por el GOES que ha 
pretendido inutilimente via privatización, la democrallzachón del crédilo. Y es que ni la nacionallzación de la banca tan ensakada por el goblemo anterior, fue capaz de fomentar el crédito a los pequefios productores. Después de haber experimentado dos mecanlsmos asignadores de recursos financleros, el crédito slgue concentrado en aclvidades agricolas de exportación tradicional.

Situación como la expuesta han tenido un efecto deprimente sobre la producción de frijol que junto al malz y el arroz constituyen la base de la alimentación del salvadorefio promedio. Sin embargo, ésto no a parecido preocuparle mucho al Estado, queremos suponer, más que por mala voluntad, una situación contingencial inesperada, para la cual el GOES no eslaba preparado.

La perspectiva de ésta problemática es el precario incremento de la producción de trijol, la cual no garantiza que en nuestro país tengamos un aceptable abastecimiento del mercado interno, puesto que la producción, como lo demuestra la historia es impredecible y las necesidades de la población están en constante crecimiento, por to que es factible (de continuar dicha tendencia), en mediano plazo, llegar al extremo de una virtual insuficiencia alimentaria. Cientamente, lo que se tiene que buscar es una salida técnica al problema y ello implica revertir la tendencia decreciente de los rendimientos (Véase cuadro \#3), pues no es racional continuar produciendo como hasta ahora. Se trata, entonces, de despertar la producción alimentaria del letargo en el que ha caldo durante este perlodo de gobierno y la manera de hacerlo es via opciones tecnológicas, pues la seguridad alimentaria en El Salvador debemos enfrentarla como un desalfo para el próximo siglo y tal como b sostiene el Dr. Josep Hodara,... los paises que no se adapten a las nuevas modalidades verán comprometida su viabilidad como entidades nacionales y económicas".

Ciertamente el desafío está planteado, habrá entonces que darle una adecuada respuesta lo más pronto posible. Alguien que no este muy enterado de nuestra realidad, podrá decir que la solución es disponer de más superticie cultivable, pero ello resulta ser poco realista pues en EI Salvador la tierra es un factor escaso e imposible de acrecentar.

Dada la poca rentabilidad del cultivo del Irijol, las tierras que son empleadas en dicha producción son marginales y de mala calidad, para la cual no existe una adecuada asistencia técnica, pues ésta al igual que el crédito se encuentra orientada fundamentalmente a la producción de bienes exportables, lo que a nuestro juicio magnilica la dificultad, de desartollar un proceso de reconversión en la producción de granos básicos de cara a hacer frente al desalío que presenta la seguridad alimen- 
taria. Sumado a lo anterior, es oportuno exponer la situación de costo beneficlo para el productor de trijol.

Cuadro No 5

Relación costo beneficlo en la producción de irljol

\begin{tabular}{crrrr}
\hline $\begin{array}{c}\text { Ario } \\
\text { agricola }\end{array}$ & Precio/Q & Ing. lotal & Costo6 T. & $\begin{array}{l}\text { Benef. } \\
\text { nelo/mz }\end{array}$ \\
\hline $1983 / 84$ & 48.25 & 550.53 & $1,317.76$ & -767.23 \\
$1984 / 85$ & 55.61 & 711.81 & $1,002.62$ & -290.81 \\
$1985 / 86$ & 75.26 & 678.85 & $1,0331.61$ & -352.76 \\
$1986 / 87$ & 97.84 & $1,228.87$ & $1,445.46$ & -216.59 \\
$1987 / 88$ & 148.34 & 882.62 & $1,335.82$ & -453.20 \\
$1988 / 89$ & 160.99 & $2,076.77$ & $1,902.67$ & 174.10 \\
$1989 / 90$ & 180.14 & $1,909.48$ & $1,727.83$ & 131.65 \\
$1990 / 91$ & 234.19 & $2,997.19$ & $2,164.59$ & 833.04 \\
\hline
\end{tabular}

Fuenle: Tomado de Rubio Roberto. Incidencia de la política económica en algunos parámetros de la seguridad alimentaria en El Salvador. Realidad Económico - Social *29.

En el cuadro amerior puede apreciarse en forma global el deterioro acumulado de el beneficio neto por manzana, que es explicado por un incremento relativo mayor de los costos totales sobre los ingresos totales, siluación que a venido a dilapidar más al pequeno productor de granos básicos, dado su tamano el productor de trijol no ejerce ningún tipo de Influencia sobre la determinación de los precios, pues éstos son delerminados por los inlermediarios, quienes compran la cosecha al productor, inclusive antes de levantarla (CDC 1993). Por el lado de los costos de producción, "el productor finalero" (ADC) necesariamente tiene que concurrir al mercado para abastecerse de insumos agrícolas y de crédito de avio. En lo referente a la compra de productos quimicos, según personeros de la ADC (Alianza Democrática Campesina) los insumos que les venden en los agroservicios son caros y de mala calidad, que en el mejor de los casos, para obtener los mismos resullados, tienen que triplicar las dosis adecuadas a la producción, para oblener Igual resultado, to que es de esperar, un aumento en los costos de producción; de igual manera los pequenos productores que logran accesar al crédito formal de la banca comercial, asumen el compromiso de pagar al banco (capital más $20 \%$ de inlerés) lo más pronlo posible, 10 
que obliga al pequefo productor a vender su cosecha al mayorista, prematuramente, para evitar caer en una situación de insolvencia económica con sus acreedores, por lamto, el productor no se benelicia de la alteración de los precios actuales, sino que por el contrario, se encuentra en una situación donde es triplemente explotado, tanto por el Intermediario mayorista como por el sistema financiero y por los agroservicios.

\section{Para quién producir?}

Las consideraciones expuestas a lo largo del presente articulo se complementan con esta üllima pregunta PARA QUIEN PRODUCIR?, la cual supone alcanzar eficiencia distributiva, es decir, el problema de la economia no solo radica en la maximización del producto sino también, como es su distribución, o sea, maximizar el producto es una meta signilicativa y necesaria, pero distribuirlo satisfactoriamente es igualmente importanle y tundamental para alcanzar crecimienlo con distribución (Desarrollo Económico).

Slendo asi, "la organización de la actividad económica se encuentra relacionada con la solución de los problemas fundamentales. Siempre con el objetivo de asegurar mayor eficiencia de sus recursos, las naciones económicamente molivadas se dedicarlan a la diflcil y controvertida búsqueda del sistema ideal".

En sistema capitalista de producción se le asigna al mercado la larea de regular toda la actividad económica, razón por la cual el mecanismo Idóneo desde la perspectiva capitalista, para distribuir eficientemente la producción es el mercado. De tal manera, si los salvadorenos queremos producir o demandar frijol tenemos obligadamente que entrar en la órbita de las senales del mercado, ateniéndonos a sus premios y castigos.

Tal como se pintan las cosas en El Salvador, el mayorista acaparador en nombre del libre mercado y en la búsqueda de su propio interés, orienta la venta del trijol hacia aquella demanda que le retribuya mejor, siendo ésta actilud nomal para una economla de mercado. El problema que se discule es si dicha actitud conduce a volcar la producción de trijol hacia el exterior, entrando en un proceso de real desabastecimiento interno del vital grano (tal como a ocumido en la actualidad) y eso no mejora la situación de los peor situados en la escala social (las mayorías populares) de éste país. 
Cuadro Na 7

El Salvedor: Comerclo externo de irjol

Perlodo 1980-1993 (1er. trimestre)

Mlles de quintales

\begin{tabular}{ccc}
\hline Anos & Exportaciones & Importaciones \\
\hline 1980 & 20.0 & 43.1 \\
1981 & 0.9 & 28.0 \\
1982 & 13.0 & 11.0 \\
1983 & 0.0 & 1.5 \\
1984 & 39.2 & 0.1 \\
1985 & 0.0 & 6.7 \\
1986 & 0.0 & 118.3 \\
1987 & 3.1 & 22.1 \\
1988 & 0.0 & 184.4 \\
1989 & 0.0 & 145.0 \\
1990 & n.d. & n.d. \\
1991 & n.d. & n.d. \\
1992 & 1.64 & 85.09 \\
1993 & 12.29 & 22.55 \\
\hline
\end{tabular}

Fuento: Cruz Letona Ricardo. La polltica de granos básicos en El Salvador. Cuadernos de investigación No. 5 CENITEC.

El comercio exterior del frijol se ha realizado básicamente con los palses Centroamericanos y muy esporádicamente con palses extraregionales. Esle comercio ha signiticado desventaja para el pals, debido a que la producción nacional de frijol no es suficiente para satisfacer los requerimlemtos internos; lo que nos lleva a confirmar, que, en materia de granos básicos, somos importadores netos y nunca hemos tenido la capacidad para colocar sostenidamente, producción nacional en el mercado de granos básicos del área centroamericana (raras ocasiones en 1980 y 1984).

Sin embargo, bajo la presente administración, los volúmenes de frijol exportado han experimentado, como lo muestra el cuadro anterior, fuertes incrementos esporádicos y un brusco incremento para el primer trimestre del presente ano ( $649 \%$ con respecto al ano anterior); situación que vuelve al producto escaso y por tanlo, caro en su precio. 
No obstante, en diversos estudios se ha determinado que El Salvador cuenta con condiciones climálicas favurables para producir masivamente bienes agricolas de alto consumo popular; condiciones que de ser aprovechadas eficientemente, permitirían a corto o mediano plazo, aumemos sustanciales en el volumen de producción a manera de satisfacer en una mayor proporción la demanda local de Irijol, en virtud de lo cual se eslaría logrando una menor dependencia de las importaciones.

Pero en la actualidad hay loda una estrategia exportadora impulsada por el GOES, que prelende penetrar a los mercados internacionales con productos no tradicionales de exportación, y en esa lógica, parte importante de la producción nacional a ido ha parar a palses de la región, con el agravanle de desabastecer el mercado interno de trijol de la economia salvadorena.

\section{Alternatlvas de soluclón}

A continuación se presentan una serie de posibles soluciones a la crisis del frijol, las cuales, por su urgencia, creemos deben ser tomadas Inmediatamente (corto plazo), y secuencialmente algunas medidas que podrian ser consideradas mediatamente en la dilicil tarea de mantener bajo un cierto control el costo de vida, como lambién aliviar las presiones alcistas en los precios de los bienes alimenticios de orlgen agricola.

1. La crisis del frijol a llegado a un nivel tal que desborda los limites económicos tolerables por las mayorlas populares de nuestro pals. que electivamenle son los que más vinculados se encuentran a la producción y al consumo del preciado grano. Por lo lanto, en condiciones extremas, como las actuales, el eslado debe establecer acciones tendientes a regular tanto la producción, la distribución como el consumo de frijol. Ello pasa necesariamente por, que el Estado incluya al frijol dentro del mecanismo de "banda de precios" vigente en nuestro pais, con lo cual se estarla creando las condiciones minimas para promover una producción eficiente de frijol a nivel nacional y por otro proteger a los productores y consumidores de las variaciones extremas de los precios intemacionales.

2. En condiciones de crisis profunda, que se expresa en una alza inmoderada en los precios, el gobierno debe manejar eficientemente la RESERVA ESTRATEGICA, ello implica, por un lado aumentar los volúmenes de dicha reserva y por otro, disponer a tiempo cuando hay distorsiones en los precios.

3. Creemos conveniente que el Eslado debe transferir totalmente los activos del desaparecido Insliluto Regulador de Abastecimiento (IRA) a las organizaciones de productores de granos básicos, para que, 
ellos por su propia iniciativa puedan comformar una base productiva fuerte que les permita ampliar su compelitividad y autonomfa. De lgual forma, es necesario que los productores tengan acceso a credlto flexible (momentáneamente) no solo para producclón (crédito de avio), sino también para la comercialización del grano.

4. Otra tarea importantisima en ese orden de cosas es la de regular los costos de producción, ello pasa por regular los precios, pero sobre lodo la calidad de los abonos tungicidas y productos químicos en general, que constiluyen los insumos requeridos para producir bienes alimenticios de origen agricola. De lgual importancla, es que nuestros pequenos productores reciban una adecuada asistencia técnica, de parte del Estado, con ello, creemos que se está generando una mayor capacidad productiva a los productores de granos básicos, con lo que estarlamos comenzando una real democratización de la agricultura.

5. Otras medidas necesarias para completar las acciones de corto plazo, son las que lienen que ver con la estructura de comercialización y la política de exporlación. El Salvador es un pals tradicionalmente importador de trijol, no somos exportadores, sencillamente, porque nunca hemos tenido un excedente de producción de granos básicos que pueda colocarse en el mercado de nuestros principales socios comerciales. Somos de la opinión, que la captación de divisas es importante como objelivo de política económica, pero, deberá ponderarse cuál es el verdadero coslo de oportunidad de desabastecer al mercado interno de frijol por ganar unos dólares más.

Creemos prioritario revisar la actual estructura de comercialización, que dicho sea de paso, resulta ser la etapa de producción mayormente beneficiada de la actual distorsión de precios. Es justo y democrático que nuevos agentes comercializadores entren a competir en el mercado de granos básicos, y éstos nuevos actores económicos, deben ser los mismos productores o representantes de éstos; si queremos promover eficientemente a éste importante sector de la población que con su trabajo manlienen la dieta de los salvadorenos.

Es pues, deseable una intervención del Estado que deliberadamente tienda a fortalecer la capacidad económica de los trabajadores del campo peor siluados, para aliviar por un lado, la tensión social que causa la marginalidad en la que vivian los productores de frijol, y garantizar a su vez, la seguridad alimentaria de la poblackón salvadorena. 


\section{Referencla blbllograllica}

Banco Central de Reserva. Revista Trimestral. Varios números.

Centro para la defensa del consumidor. Resultado de investigación de precios de productos básicos en establecimientos comerciales de San Salvador, enero 1993.

Chong Dlaz Sonia. La polltica de precios de los granos básicos en El Salvador. Tesis de grado en Economia, octubre 1992.

FUSADES, Informe económico semanal. 25 de noviembre de 1992, N 48.

Latino-Economla, miércoles 19 de mayo 1993. № 82.

Letona Ricardo, La polltica de granos básicos en El Salvador: análisis y recomendaciones. Cuaderno de investigación N 25 . CENITEC.

Ministerio de Agricultura y Ganaderla, Dirección semanal de Economía Agropecuaria, Estadlsticas Agropecuarias. Varios números.

Rubio Roberto, Incidencia de la Política Económica predominanle en algunos parámetros de la seguridad alimentaria en El Salvador. Realidad Económico-Social Ne 29. 